\title{
A comprehensive earthquake catalogue for Nepal and its adjoining region
}

\author{
*Sudhir Rajaure ${ }^{1}$ and Lalu Prasad Paudel ${ }^{2}$ \\ ${ }^{1}$ Department of Mines and Geology, Lainchaur, Kathmandu, Nepal \\ ${ }^{2}$ Central Department of Geology, Tribhuvan University, Kirtipur, Kathmandu, Nepal \\ *Corresponding author: srajaure@gmail.com
}

\begin{abstract}
We have prepared a comprehensive earthquake catalogue for Nepal and its adjoining region. The catalogue contains magnitude homogenized independent earthquakes of magnitude (Mw) between 4.0 and 8.5, which occurred between 1100 AD and 2018 AD. The catalogue contains date, time, latitude, longitude, depth, and magnitude of earthquakes, which are required in the study of seismic activity, tectonics and seismic hazard. Primary earthquake catalogues were collected from the International Seismological Centre (ISC, 2015), United States Geological Survey (USGS), which contain instrumentally recorded earthquake data and date back to 1900 AD. These primary catalogues of instrumentally recorded earthquakes were supplemented by historical earthquakes reported in published literatures, which occurred before $1900 \mathrm{AD}$. The collected primary catalogues were compiled and processed to develop a comprehensive catalogue. The developed comprehensive catalogue is expected to serve as a basic database for the study of seismic activity and seismic hazard in Nepal and its adjacent area.
\end{abstract}

Keywords: Completeness analysis, Recurrence relation, Declustering, Magnitude of completeness

Paper Received: 28 Mar 2017

Paper Accepted: 31 May 2018

\section{INTRODUCTION}

Earthquake catalogues provide us basic earthquake information such as the time of earthquake occurrence, their hypocenter locations (latitude, longitude and depth), and magnitudes. The catalogues are often complemented by additional information like damage or other effects. Earthquake catalogues are important in the studies of seismotectonics, seismicity, earthquake physics and hazard analysis (Woessner and Wiemer, 2005). The earlier instrumental records (before 1960) usually had low resolution in time and amplitude, which were manually analyzed. The present instruments and their records are different; the high-resolution digital records are analyzed either interactively or fully automated with the help of an expert.

To understand the seismic activity, seismotectonics and seismic hazard of a region, a complete and magnitudehomogenized catalogue of independent earthquakes is required. The catalogue should contain historical, as well as instrumentally recorded data of earthquakes. Such a catalogue provides us the most direct information of the seismic activity of the region considered.

In Nepal, earthquake catalogues have been prepared specifically for previous studies on seismic hazard assessment by various institutions and researchers (e. g., GSHAP, NBC105, Pandey et al., 2002; Thapa and Wang, 2013. Ojha et al. (2013) published a catalogue for Nepal for the period between $1255 \mathrm{AD}$ and $2012 \mathrm{AD}$. These works have compiled data which were available by the time of their completion and do not agree with each other in terms of time of coverage.
This work has been undertaken to develop a composite and comprehensive catalogue of independent earthquakes collecting primary earthquake catalogues from various sources and literatures published till 2017.

\section{METHODOLOGY}

\section{Data collection}

Primary earthquake catalogues are fundamental inputs in the development of a comprehensive catalogue. Two types of primary catalogues were collected in this study: instrumentally recorded catalogues reported by various seismological agencies and historical catalogues reported in published literatures. Collected catalogues contain date, origin time, latitude, longitude, depth, magnitude and magnitude type of selected earthquakes, the locations of which fall in a rectangular region between $25^{\circ}$ $\mathrm{N}$ and $32^{\circ} \mathrm{N}$ latitude and $78^{\circ} \mathrm{E}$ and $92^{\circ} \mathrm{E}$ longitudes.

Catalogues of instrumentally recorded earthquakes were collected from the International Seismological Centre (ISC) and the United States Geological Survey (USGS), which date back to $1901 \mathrm{AD}$ (Fig. 1, Table 1). The ISC catalogue contains 5426 earthquakes of magnitude range between 1.2 and 8.2 since 1901 AD (Table 1, Fig. 1). Similarly, the USGS catalogue contains 2056 earthquakes of magnitude range between 3 and 8 since 1908 AD (Table 1, Fig. 1).

Catalogues of the historical (pre-instrumental) earthquakes were collected from published literatures (e. g., Bilham et al., 2004; Ambrasseys and Douglas, 2004; Chitrakar and Pandey, 
Table 1: Earthquake data collected from different sources.

\begin{tabular}{lllllllc}
\hline S. N. & Source & From & To & $\begin{array}{l}\text { Minimum } \\
\text { magnitude }\end{array}$ & $\begin{array}{l}\text { Maximum } \\
\text { magnitude }\end{array}$ & Number & $\begin{array}{l}\text { After } \\
\text { compilation }\end{array}$ \\
\hline 1 & USGS & 1908 & 2017 & 3 & 8 & 2056 & 5451 \\
2 & ISC & 1901 & 2017 & 1.2 & 8.2 & 5426 & \\
\hline
\end{tabular}

1986; Lave et al., 2005; Szeliga et al., 2010). Data of historical earthquakes is available for strong earthquakes only which reportedly caused considerable destruction in the past. The location and magnitude of historical earthquakes were calculated using empirical relations and macroseismic data of earthquakes (e. g. destruction pattern, liquefaction pattern, and result of paleoseismic investigations). The location and magnitude of historical earthquakes are typically estimated from the intensity of ground shaking and its geographical distribution. Therefore, the location and magnitude of historical earthquakes, typically, might have large uncertainties in comparison to those of instrumentally recorded earthquakes.

The collected primary catalogues were merged into a composite catalogue. The composite catalogue was checked for duplicate events and such duplicate events were removed from the catalogue. The total number of earthquakes in the composite catalogue is 5451 for the magnitude range between 1.2 and 8.2.

\section{Magnitude conversion}

The composite earthquake catalogue contains earthquakes collected from different sources (Table 1, Fig. 1), which have reported different types of magnitudes (e. g., moment magnitude $(\mathrm{Mw})$, body wave magnitude $(\mathrm{Mb})$, surface wave magnitude (Ms) and local magnitude (Ml)). Moment magnitude is generally considered the best overall estimate of an earthquake size and does not saturate even at large earthquakes (Kanamori, 1977; Hanks and Kanamori, 1979), therefore it is preferred in the study of seismic activity, seismotectonics and seismic hazard.

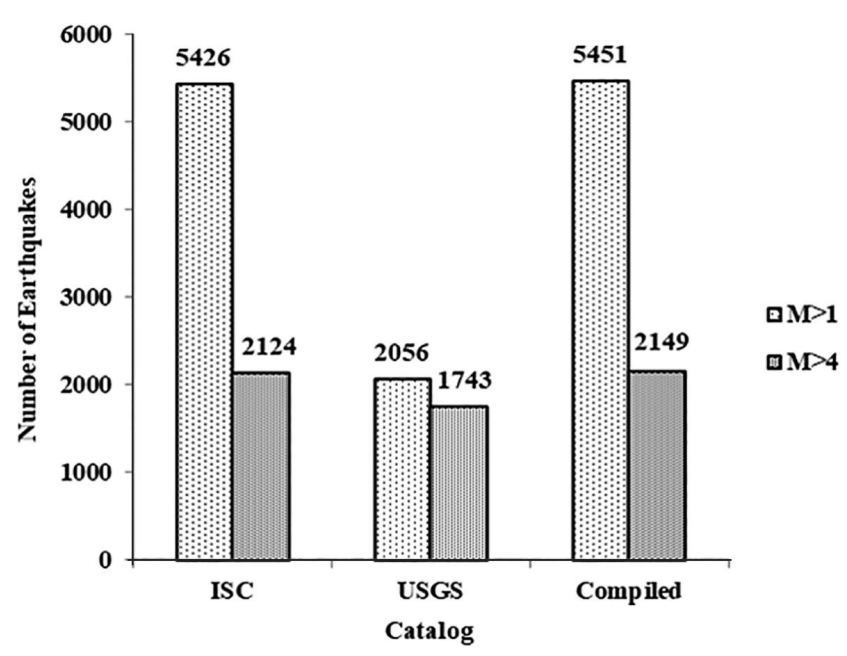

Fig. 1: Earthquake data collected and compiled in this study. The instrumentally recorded (ISC and USGs) and historical earthquakes were merged into the 'Composite' catalogue.
In order to develop a comprehensive catalog of consistent magnitude, the other type of magnitudes ( $\mathrm{Mb}$, Ms and $\mathrm{Ml}$ ) were converted into moment magnitude (Mw) using the empirical relations (Equation (1), Equation (2) and Equation 3) from Scrodilis (2006). The number of $\mathrm{Mw}>4.0$ earthquakes increased after magnitude conversion, which is demonstrated by Fig. 1 and Fig. 7. Other characteristics of the catalogue are presented in Fig. 2 and Fig. 3.

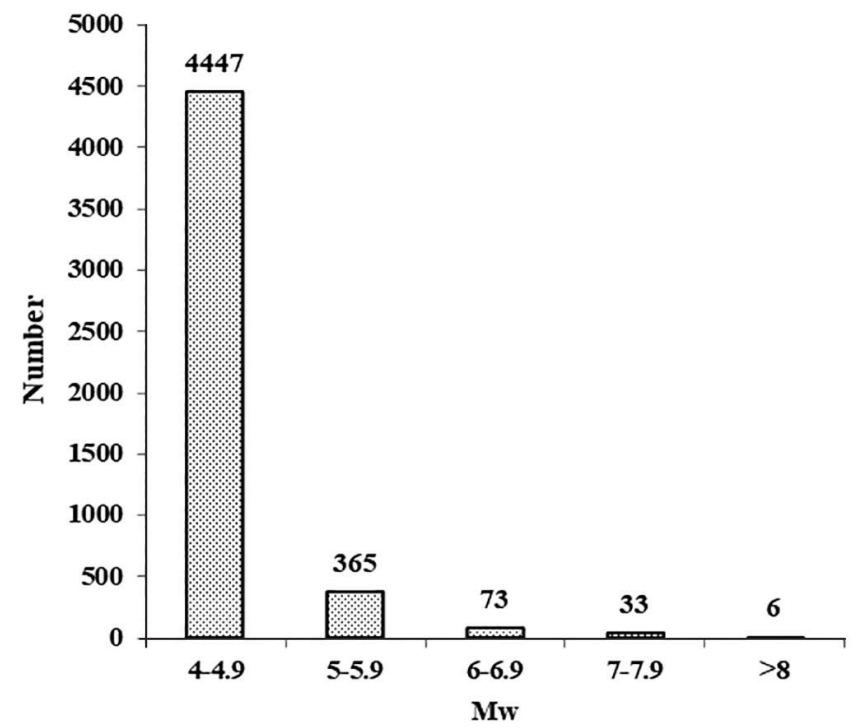

Fig. z: Number ot earthquakes tor ditterent magnitude class after magnitude conversion

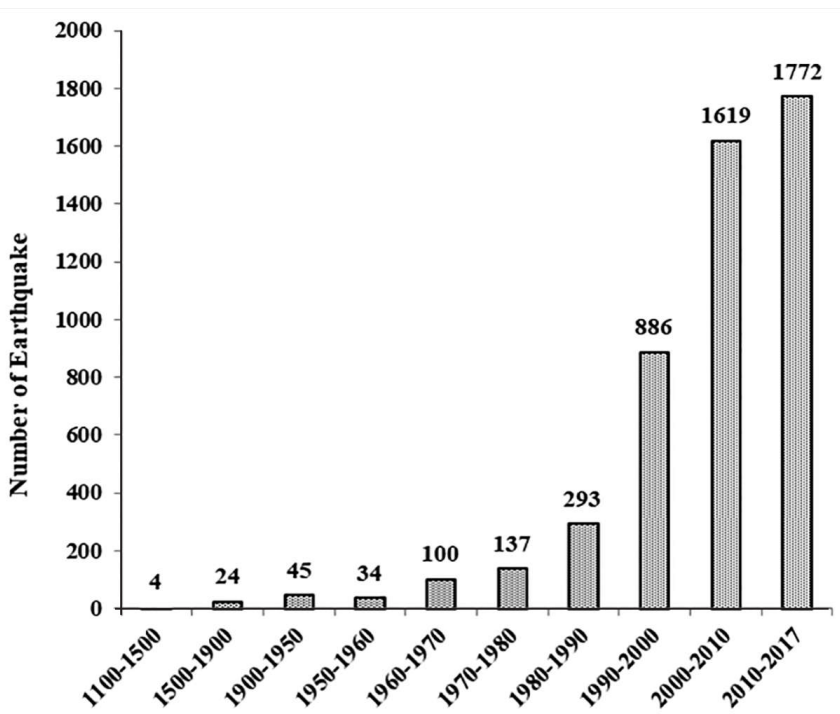

Fig. 3: Number of earthquakes $(\mathrm{Mw}>4)$ for different time intervals (after magnitude conversion) 
$\mathrm{Mw}=0.67( \pm 0.005) * \mathrm{MS}+2.07( \pm 0.03)$

Eq. (1)

(For shallow earthquakes (depth $<70 \mathrm{Km}$ ) and $\mathrm{Ms}$ between 3.0 and 6.1),

$\mathrm{MW}=0.99( \pm 0.02) * \mathrm{MS}+0.08( \pm 0.13)$

(for Ms between 6.2 and 8.2)

$\mathrm{MW}=0.85( \pm 0.04) * \mathrm{mb}+1.03( \pm 0.23)$

(for $\mathrm{Mb}$ between 3.5 and 6.2)

\section{Declustering}

An earthquake catalogue may contain fore-shocks and aftershocks in addition to mainshocks. A large size earthquake is generally followed by a large number of aftershocks and sometimes it is preceded by foreshocks. The foreshocks and aftershocks are dependent events to the mainshock (Fig. 4). In the study of seismotectonics, seismic activity and probabilistic seismic hazard assessment, a catalogue of independent earthquakes is required which follow the Poisson distribution (e. g., Gardner and Knopoff, 1974; Shearar and Stark, 2011; Abrahamson, 2006).

We used "Cluster 2000" code (USGS) to identify and remove dependent events in the catalogue following Gardner and Knopoff (1974) method. The code is freely available on website of the USGS (\#CLUSTER). The code uses spatio- temporal window with reference to the mainshock to identify and remove the dependent events. The seismicity after declustering is presented in Fig. 5. The magnitude of completeness in the declustered catalogue is Mw 4 (Fig. 6).

\section{Completeness Test}

The developed catalogue contains earthquakes of a range of magnitudes, which are not available for the entire span of time (1100 AD to $2017 \mathrm{AD}$ ). Large events are reported for longer time but the small earthquakes are reported for short time (Fig. 8).

To assess completeness of different magnitude classes, we followed the Stepp (1972) technique. The technique divides an earthquake catalogue into $(\mathrm{T})$ time intervals and the magnitude range into (n) magnitude classes. This test relies on the statistical property of the Poisson distribution that highlights time intervals during which the recorded earthquake occurrence rate does not change. The test evaluates the stability of the mean rate of occurrences $(\lambda)$ of events which fall in a predefined magnitude range in a series of time windows $(\mathrm{T})$. If the rate of occurrence $\lambda$ is constant, then the standard deviation of the rate $(\sigma)$ varies as $1 /(\mathrm{T})^{0.5}$ and $\lambda$ is not stable if $\sigma$ deviates from the straight line of the $1 /(\mathrm{T})^{0.5}$ slope. The length of the time interval for which the standard deviation does not vary from the straight line is the time interval of completeness for that particular magnitude class. The complete time interval of each magnitude class is visually determined from the plots.

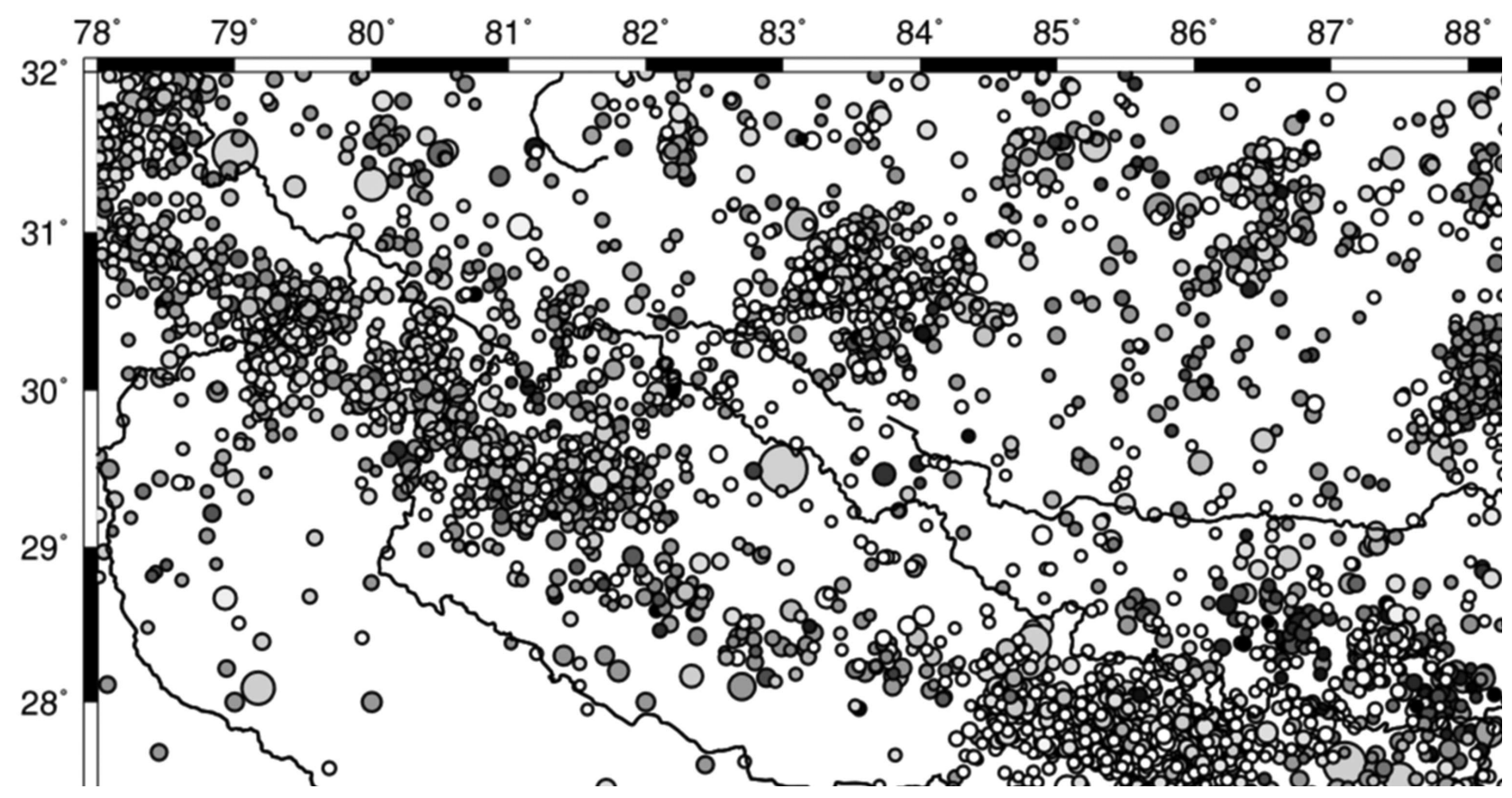

Fig. 4: Epicenter distribution before declustering the composite catalogue. The clusters noticed in the figure are dependent events. The dense cluster in Central Nepal represents the aftershocks of the 2015 Gorkha Earthquake. The scale stands for depth $(\mathrm{km})$. 


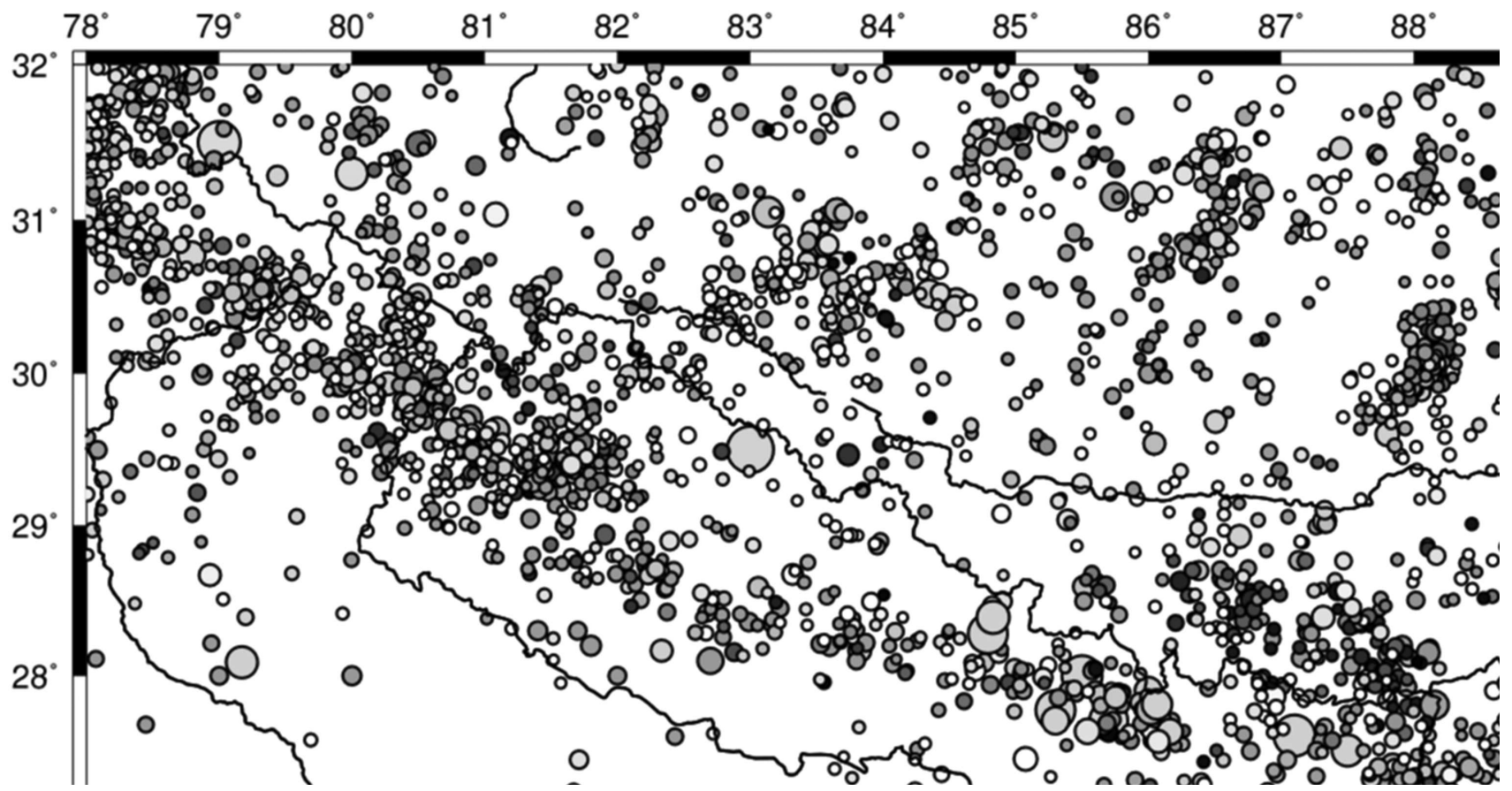

Fig. 5: Epicenter distribution after declustering of the compiled catalogue. Note that the clusters of aftershocks disappear after declustering. The scale stands for depth $(\mathbf{k m})$

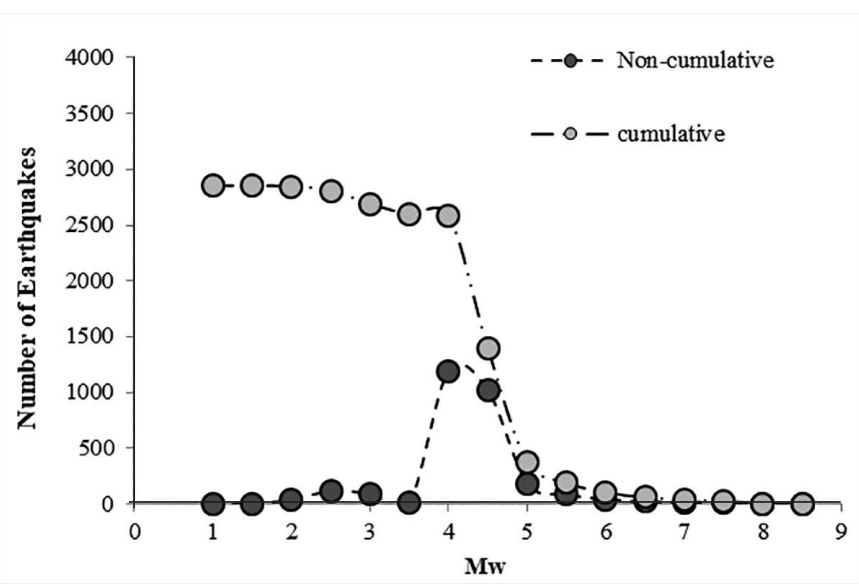

Fig. 6: Cumulative and non-cumulative distribution of earthquake for different magnitude ranges (ISC catalogue). The magnitude of completeness (Mc) for the study area is Mw 4.0

In order to determine the completeness levels for different magnitude classes, the catalogue was split into 8 time windows of 100-year length between 1100 (first data entry in the catalogue) before $1900 \mathrm{AD}$ and 11 time windows of 10-year length after 1900 AD (Fig. 9). A summary of magnitude classes and their respective complete time intervals $(\mathrm{T})$ are presented in Fig. 10.

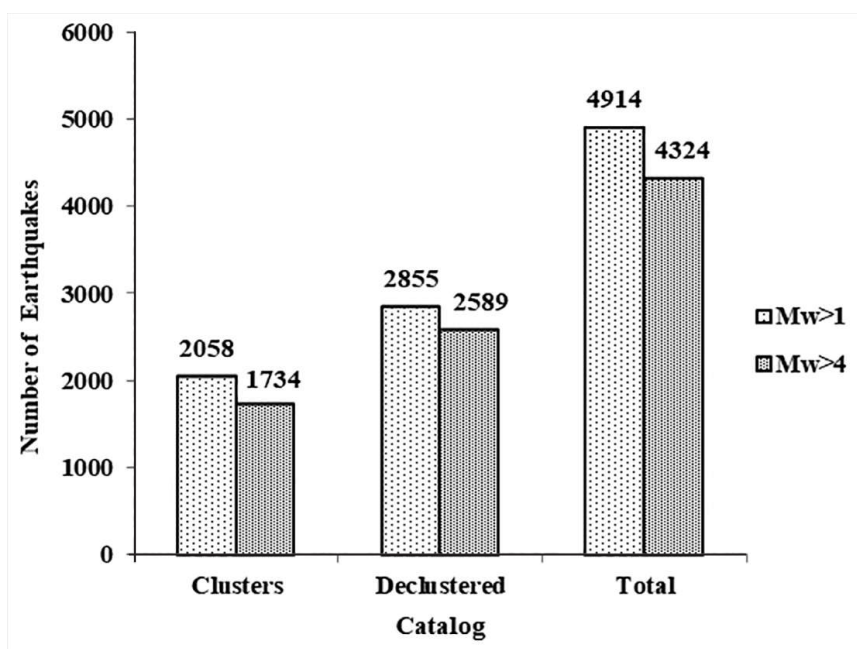

Fig. 7: The number of earthquakes in the catalogues before and after the declustering process is applied.

\section{Gutenberg-Richter relation}

The Gutenberg-Richter relation is an empirical relation between the magnitude $(\mathrm{m})$ of earthquake and number $(\mathrm{N})$ of earthquakes with magnitude larger than ' $\mathrm{m}$ '. It is a remarkable feature of worldwide seismicity (Warner and Laura, 2003), which is used to describe seismic activity (Takeo and Shimazaki, 

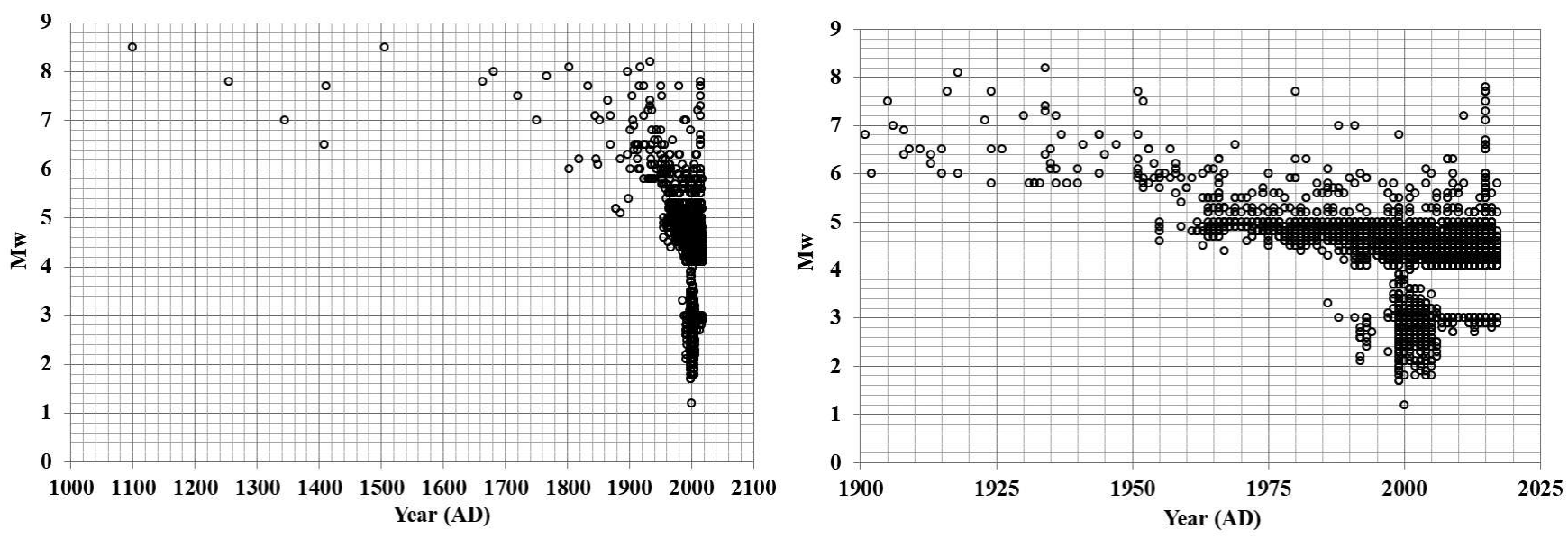

Fig. 8: Availability of earthquake size in different time

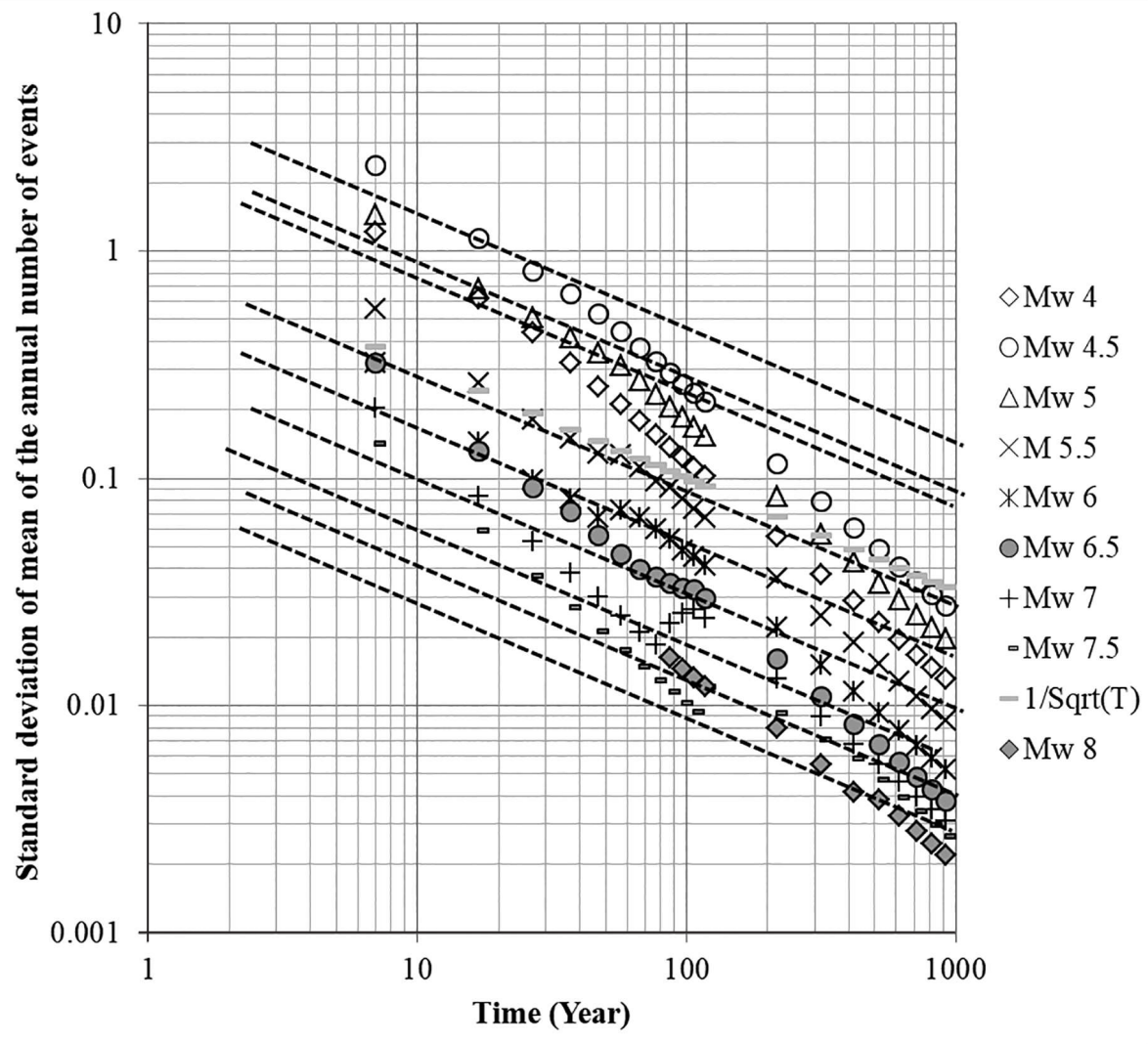

Fig. 9: Completeness test of homogenized composite catalogue following Stepp (1972) technique

2008). Ishimoto and Iida (1939) and Gutenberg and Richter (1944) proposed the relation in the following form.

$$
\log _{10}(\mathrm{Nm})=a-b * m
$$

Where ' $\mathrm{N}$ ' is the number of earthquakes per year with magnitude equal to or larger than $m$. The $a$ and $b$ in the equation are coefficients called a value and b value respectively. The avalue' describes total activity of earthquakes in the region whereas the $b$ value gives relative number of large and small earthquakes. When the $b$ value increases, the number of large earthquakes decreases compared to the number of smaller magnitudes and vice versa. For active tectonic regions $b$ value is about 1 and for volcanic regions it is up to 2 or higher. The $\mathrm{a}$ and $\mathrm{b}$ value are fundamental seismic parameters required in probabilistic seismic hazard analysis. The b value is estimated using least square method or the maximum likelihood method. 


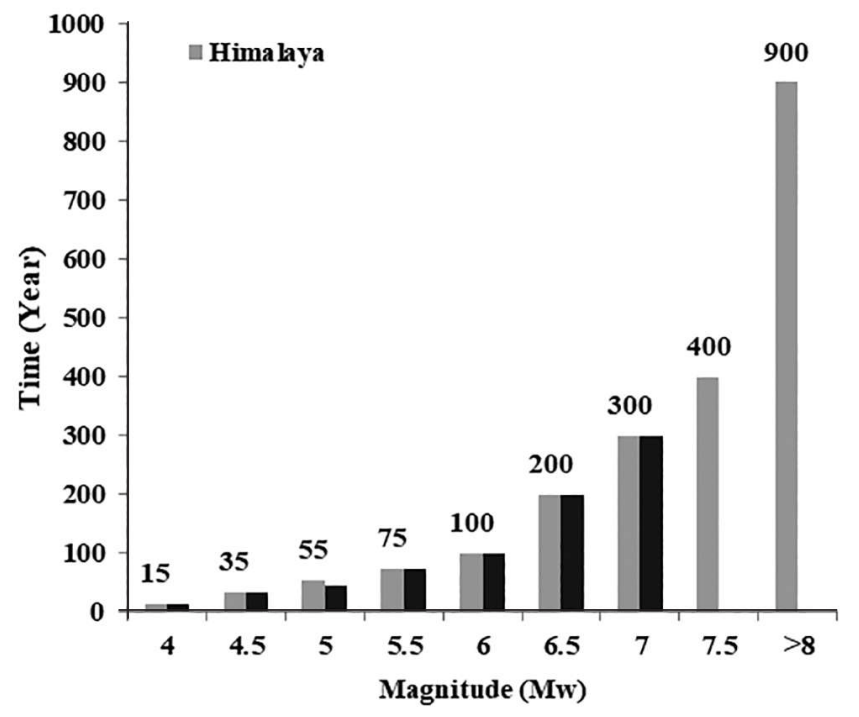

Fig. 10: Completeness of different magnitude classes for Himalaya and South Tibet

Table 2: Recurrence parameters for two tectonic zones (Himalaya and South Tibet)

\begin{tabular}{llll}
\hline Region & Method & 'a' value 'b' value \\
\hline \multirow{2}{*}{ Himalaya } & Maximum likelihood & 5.3 & 0.9 \\
& Least square & 5.2 & 0.95 \\
\multirow{2}{*}{ South Tibet } & Maximum likelihood & 6.5 & 1.19 \\
& Least square & 5.9 & 1.1 \\
\hline
\end{tabular}

The common technique to estimate $b$ value is the least squares fit, which can lead to biased result and apparent errors may be much smaller than the real ones. The maximum likelihood method of Aki (1965) is the most accurate method to calculate ' $b$ ' value, but it requires large data sets. Monte Carlo simulations and equations from Aki (1965) indicate that a minimum of 2000 earthquakes are required to calculate ' $b$ ' to within 0.05 at $98 \%$ confidence.

In the Nepal Himalaya, the earthquakes in the south of the $3500 \mathrm{~m}$ elevation contour line, in majority, are overwhelmingly found to have thrust mechanism, whereas those in the north and above $3500 \mathrm{~m}$ contour line, in majority, have normal fault mechanism (e. g., Rajaure et al., 2013). Earthquakes in south Tibet, close to the Nepal-China border in north-east show strike-slip mechanisms (e. g., Rajaure et al., 2013). To estimate the $a$ and $b$ value the prepared catalogue was divided into two sub-regions (Himalaya and South Tibet) following the mechanism of deformation in the region. The recurrence parameters were estimated using the least square and maximum likelihood method (Table 2, Fig. 11, and Fig. 12) for the Himalaya and South Tibet, respectively.

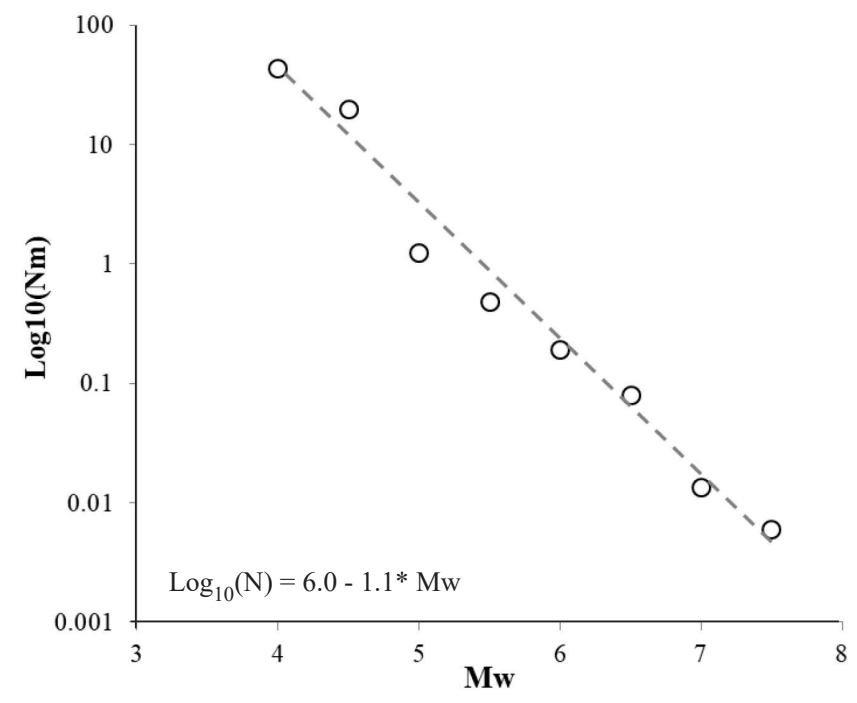

Fig. 11: Gutenberg-Richter relation for earthquakes in South Tibet

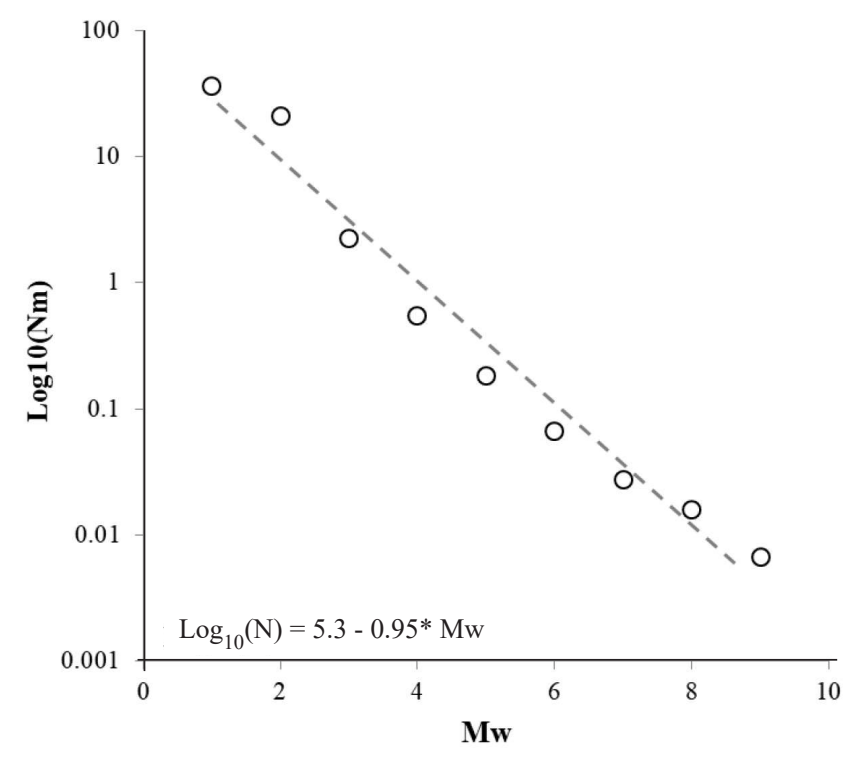

Fig. 12: Gutenberg-Richter relation for earthquakes in the Nepal Himalaya

\section{CONCLUSIONS}

A comprehensive and composite catalogue has been prepared for Nepal and its adjoining region between $25 \mathrm{~N}$ and $32 \mathrm{~N}$ latitude and $78 \mathrm{E}$ and $92 \mathrm{E}$ longitudes. The developed catalogue contains 2589 events with Mw between 4.0 and 8.5, for the period between $1100 \mathrm{AD}$ and $2017 \mathrm{AD}$ and the magnitude of completeness $(\mathrm{Mc})$ is $\mathrm{Mw} 4.0$.

A completeness test of the catalogue was performed for South Tibet and the Himalaya separately as they represent two types of stress regimes, i. e. extensive and compressive, respectively (e. g. Rajaure et al., 2013). The catalogue is 
complete for large earthquakes $(\mathrm{Mw}>8.0)$ for the entire span of time (since $1100 \mathrm{AD}$ ) but is underreported for small magnitude earthquakes. The completeness of small earthquakes improved in the late 20th century, following the advent, continuous development and expansion of instrumental networks. The completeness test of the catalogue revealed that $\mathrm{Mw} 4,4.5,5$, 5.5, 6, 6.5, 7, 7.5 and larger than $\mathrm{Mw} 8$ are complete for 15, $35,55,75,100,200,300,400$ and 900 years, respectively for the Himalaya and $\mathrm{Mw} 4,4.5,5,5.5,6,6.5,7$ are complete for $15,35,55,75,100,200,300$ years in their order for South Tibet.

Earthquake recurrence parameters are estimated in south Tibet and Himalaya separately; our analysis shows that strong earthquakes are more common in the Himalaya than in South Tibet.

The result of this work is expected to be useful in the study of seismotectonics, earthquake activity and seismic hazard assessments.

\section{ACKNOWLEDGEMENTS}

We express our sincere thanks to the Editorial Board of the journal. We are grateful to two anonymous reviewers for providing their valuable comments for the improvement of the first version of the manuscript. Similarly, we extend our thanks to all those who helped us to bring this work in its present form.

\section{REFERENCES}

Abrahamson, N A., 2006, Seismic hazard assessment: Problems with current practice and future developments. Proceedings of the First European Conference on Earthquake Engineering and Seismology, Geneva, p. 17.

Aki, K., 1965, Maximum Likelihood estimate of $b$ in the formula $\log \mathrm{N}=\mathrm{a}-\mathrm{bM}$ and its confidence limits. Bulletin of Earthquake Research Insttitute, v. 43, pp. 237-239.

Ambraseys, N. and Douglas, J., 2004, Magnitude calibration of north Indian earthquakes. Geophysics Journal International, v. 159, pp. 165-206.

Bilham, R., Bodin, P., and Jackson, M., 1995, Entertaining a great earthquake in western Nepal. Journal of Nepal Geological Society, v. 11 (1), pp. 73-78.

Chitrakar, G. R. and Pandey, M. R., 1986, Historical earthquakes of Nepal, Bulletin of the Nepal Geological Society, v. 4, pp. 7-8.

Gardner, J. K. and Knopoff, L., 1974, Is the sequence of earthquakes in Southern California, with aftershocks removed, poissonian? Bulletin of the Seismological Society of America, v. 64/5, pp. 1363-1367.

Gutenberg, B. and C. Richter, 1954, Seismicity of the Earth and Associated Phenomena (Princeton University Press, Princeton, New Jersey), 2nd edition, pp. 310.
Gutenberg, B., and C. F. Richter, 1944, Frequency of earthquakes in California. Bulletin of the Seismological Society of America, v. 34, pp. 184-188.

Hanks, T. C. and Kanamori, H., 1979. A moment magnitude scale. Journal of Geophysical Research, v. 84, pp. 2348-2350.

International Seismological Centre, 2015, On-line Bulletin, http://www.isc.ac.uk, International . Seismological. Centre., Thatcham, United Kingdom.

Ishimoto, M. and Iida, K. 1939, Observations sur les seims euregistr'e par le microseisograph construite dernierment (I). Bulletin of the Earthquake Research Institute-University of Tokyo, v. 17, pp. 443-478.

Kanamori, H., 1977, The energy release in great earthquakes. Journal of Geophysical Research, v. 82, pp. 2981-2987.

Lave, J., Yule, D., Sapkota, S. N., Basant, K., Madden, C., Attal, M., and Pandey, R., 2005, Evidence for a Great Medieval Earthquake ( 1100 A.D.) in the Central Himalayas, Nepal. Science, v. 307, pp. 1302-1305. CHECK Pandey, M. R. or only R??? (Checked: it's a mistake in the article. It should have been Pandey M. R. in fact)

Ojha S., Bhattarai G. K., and Rajaure S., 2013, A catalog for Nepal Himalaya earthquakes from 1255 to 2012. International Journal of Landslide and Environment, v. 1, $\mathrm{p} 3$.

Pandey, M. R., Tandukar, R. L. P., Lave, J. P., and Massot, J. P., 1995, Interseismic Strain Accumulation on the Himalayan Crustal Ramp, Nepal. Geophysical Research Letters, v. 22 (7), pp. 751-754.

Pandey, M. R., Tandukar, R. P., Avouac, J. P., Vergne, J., and Heritier, T., 1999, Seismotectonics of the Nepal Himalaya from a local seismic network. Journal of Asian Earth Sciences, v. 17, pp. 703-712.

Rajaure, S., Sapkota, S. N., Adhikari, L. B., Koirala, B., Bhattarai, M., Tiwari, D. R., Gautam, U., Shrestha, P., Maske, S., Avouac, J. P., Bollinger, L., and Pandey, M. R., 2013, Double difference relocation of local earthquakes in the Nepal Himalaya. Journal of Nepal Geological Society, v. 46, pp. 133-142

Scordilis, E. M., 2006, Empirical global relations converting $\mathrm{MS}$ and $\mathrm{mb}$ to moment magnitude. Journal of Seismology, v. 10, pp. 225-236.

Shearer, P. M. and Stark, P. B., 2011, Global risk of big earthquakes has not recently increased. Proceedings of the National Academy of Sciences, v. 109, pp. 717-721.

Stepp, J. C., 1972, Analysis of the completeness of the earthquake sample in the Puget Sound area and its effect on statistical estimates of earthquake hazards. Proceedings of International Conference on Microzonation for Safer Construction, Research, and Application, Seattle, Washington University, v. 2, pp. 897-909. 
Szeliga, W., Hough, S., Martin, S., and Bilham, R., 2010, Intensity, Magnitude, Location, and Attenuation in India for Felt Earthquakes since 1762. Bulletin of the Seismological Society of America, v. 100 (2), pp. 570-584.

Takeo I., and Kunihiko S., (2008), The Gutenberg-Richter relationship vs. the characteristic earthquake model: effects of different sampling methods. Bulletin of Earthquake Research Insitute, Univeristy of Tokyo, v. 83, pp. 131-151

Thapa, D. R., and Wang G., 2013, Probabilistic seismic hazard analysis of Nepal. Earthquake Engineering and Engineering Vibration, v. 12 (4), pp. 577-586.

United States Geological Survey, On-line Bulletin, . United States Geological Survey, Golden, USA
Utsu, T., 1965, A method for determining the value of $b$ in the formula $\log \mathrm{N}=\mathrm{a}-\mathrm{bM}$ showing the magnitude-frequency relation for earthquakes. Geophysics. Bulletin of Hokkaido University, v. 13, pp. 99-103

Warner, M. and Laura, S., 2003, A review and new insights on the estimation of the b-value and its uncertainty. Annals of Geophysics v. 46 (6), pp. 1271-1282.

Woessner, J., and Wiemer S., 2005, Assessing the quality of earthquake catalogs: Estimating the magnitude of completeness and its uncertainty. Bulletin of the Seismological Society of America, v. 95, pp. 684-698. 